\title{
The Adjunctive Effect of Nebulized Furosemide in COPD Exacerbation: A Randomized Controlled Clinical Trial
}

\author{
Hojat Sheikh Motahar Vahedi MD, Babak Mahshidfar MD, Helaleh Rabiee MD, \\ Soheil Saadat MPH PhD, Hamid Shokoohi MD MPH, Mojtaba Chardoli MD, \\ and Vafa Rahimi-Movaghar MD
}

\begin{abstract}
OBJECTIVE: To examine the effect of nebulized furosemide as an adjunct to the conventional treatment of patients with COPD exacerbation in an emergency department. METHODS: In this randomized double-blinded clinical trial, patients with COPD exacerbation were randomized to receive $40 \mathrm{mg}$ nebulized furosemide or placebo as an adjunct to the conventional treatments. We recorded changes in dyspnea severity (measured with a visual analog scale), $\mathrm{FEV}_{1}$, arterial blood gas measurements, blood pressure, heart rate, and breathing frequency at baseline and 1 hour after treatment. RESULTS: We randomized 100 patients, whose mean age was $73.1 \pm 8.7 \mathrm{y}$. The measured variables all improved significantly in both groups. $\mathrm{FEV}_{1}$, dyspnea, $\mathrm{pH}$, mean blood pressure, and heart rate improved significantly more in the furosemide group. CONCLUSIONS: Nebulized furosemide benefits patients with COPD exacerbation. Key words: COPD; dyspnea; nebulized furosemide; bronchodilation; arterial blood gas. [Respir Care 2013;58(11):1873-1877. () 2013 Daedalus Enterprises]
\end{abstract}

\section{Introduction}

Dyspnea is a common and overriding symptom of COPD, and contributes to activity limitation, anxiety, and poor

\footnotetext{
Dr Sheikh Motahar Vahedi is affiliated with the Emergency Department, Shariati Hospital, Tehran University of Medical Sciences, Tehran, Iran. Dr Mahshidfar is affiliated with Emergency Department, Hazrat-ERasoul Hospital, Tehran University of Medical Sciences, Tehran, Iran. Drs Rabiee, Saadat, and Rahimi-Movaghar are affiliated with Trauma and Surgery Research Center; and Dr Chardoli is affiliated with the Emergency Department, Sina Hospital, Tehran University of Medical Sciences, Tehran, Iran. Dr Shokoohi is affiliated with the Department of Emergency Medicine, George Washington University, Washington, DC. Dr Rahimi-Movaghar is also affiliated with the Research Centre for Neural Repair, University of Tehran, Tehran, Iran.
}

The authors have disclosed no conflicts of interest.

This study was the postgraduate thesis of Dr Sheikh Motahar Vahedi, in cooperation with Dr Mahshidfar as an attending professor of emergency medicine.

Correspondence: Babak Mahshidfar MD, Emergency Department, Hazrat-E-Rasoul Hospital, Tehran University of Medical Sciences, Tehran, Iran.E-mail: b-mahshidfar@tums.ac.ir; Vafa Rahimi-Movaghar MD, Sina Trauma and Surgery Research Center, Tehran University of Medical Sciences, Tehran, Iran. E-mail: v_rahimi@tums.ac.ir.

DOI: $10.4187 /$ respcare. 02160 quality of life..$^{1-4}$ In spite of the prevalence and burden of dyspnea, its effective management remains a challenge for physicians and calls for the exploration of new treatments. ${ }^{3,5}$ Irreversible underlying changes to the lungs in patients with COPD often make it difficult to improve dynamic ventilatory mechanics in acute dyspnea states. Therefore, in complement to the therapies that target the underlying causes, the care of dyspnea has shifted to improve dyspnea by using medications that modulate the bronchopulmonary vagal afferent activity. ${ }^{6-9}$ Some studies have found that inhaled furosemide, a common diuretic, alleviates dyspnea by modulating vagal afferent activity in animal lung models, ${ }^{10}$ reduces induced dyspnea in healthy subjects, ${ }^{11,12}$ and might be effective against dyspnea in patients with asthma ${ }^{13}$ and lung cancer. ${ }^{14,15}$ Ong et $\mathrm{al}^{16}$ and Jenson et al ${ }^{17}$ evaluated the efficacy of inhaled furosemide in COPD patients, and supported its use as a therapy in patients with COPD exacerbation. ${ }^{3,5,17,18}$ Studies of inhaled furosemide in COPD were mainly conducted in stable patients with induced dyspnea; therefore, the short-term effect of nebulized furosemide in COPD exacerbation has not been investigated. We evaluated nebulized furosemide as an adjunct to conventional therapy in the management of patients with COPD exacerbations in an emergency department. 


\section{The Adjunctive Effect of Nebulized Furosemide in COPD Exacerbation}

\section{Methods}

In this randomized, double-blinded, clinical trial, a convenience sample of patients was enrolled in the emergency department of Hazrat-e-Rasoul Hospital, a tertiary medical center of Tehran University of Medical Sciences, Tehran, Iran, between November 2009 and March 2010. The study was performed in accordance with the declaration of Helsinki, and was approved by our institutional review board (study 139). All subjects or their next of kin provided written informed consent before being included in the study. The subjects and the clinicians who administered the interventions were blinded to the medications.

The inclusion criteria were: COPD and presentation with COPD exacerbation, age $\geq 18$ years, and clinically stable with no need for mechanical ventilation. COPD was defined according to the standards of the American Thoracic Society and the Global Initiative for Chronic Obstructive Lung Disease guideline, ${ }^{1,19}$ in which worsening of dyspnea of COPD within 24 hours of hospital admission indicates dyspnea exacerbation. Patients with history of asthma, atopy, congestive heart failure, or lung cancer were excluded.

Ong et al reported $42 \%$ improvement in their intervention group, compared to $15 \%$ in their placebo group. ${ }^{16} \mathrm{We}$ used statistics software (StataCorp, College Station, Texas) to estimate the minimum required sample size to detect a similar difference, with the type 1 and type 2 errors both set at $5 \%$, and the sample size calculation was 78 subjects. To cope with the possibility of non-adherence, drop-outs, and/or missed or excluded measurements, 100 patients were recruited. We used statistics software (SPSS 15, SPSS, Chicago, Illinois) to randomize the subjects into the intervention and placebo groups. Daily, an assistant who was not involved with the subjects' care blindly provided the medication/placebo by filling 10 similar vials, labeled 1 or 2, with $4 \mathrm{~mL}$ furosemide $(20 \mathrm{mg} / 2 \mathrm{~mL}$, Caspian Tamin Pharmaceutical, Tehran, Iran) or $4 \mathrm{~mL} 0.9 \%$ saline. The furosemide group received vials labeled 1 . The saline group received vials labeled 2 .

On admission to the study, we measured heart rate, breathing frequency, mean arterial blood pressure, $\mathrm{FEV}_{1}$ (Spirolab II, MIR Medical International Research, Rome, Italy), and arterial blood gases, including $\mathrm{pH}, \mathrm{P}_{\mathrm{aCO}_{2}}, \mathrm{P}_{\mathrm{aO}}$, $\mathrm{HCO}_{3}{ }^{-}$, and oxygen saturation.

We measured dyspnea with a visual analog scale that had a horizontal line with 10 equally spaced markers, ranging from 0 (no shortness of breath) to 10 (the worst shortness of breath). Shortness of breath was described as an urge to breathe. The subjects were asked to point to one ordinal number from 0 to 10 to express the severity of dyspnea. Arterial gas samples were obtained via the radial artery, while breathing room air; the samples were analyzed within 30 min.

\section{QUICK LOOK}

\section{Current knowledge}

Dyspnea is a common symptom in COPD, and reduces functional capacity and quality of life. Routine treatment for dyspnea in COPD exacerbation includes bronchodilators, oxygen, and noninvasive ventilation.

\section{What this paper contributes to our knowledge}

The addition of inhaled furosemide to traditional therapy for COPD exacerbation reduced dyspnea and increased $\mathrm{FEV}_{1}$, compared to traditional therapy alone. Inhaled furosemide, a common diuretic, may alleviate dyspnea by modulating vagal afferent activity.

All subjects received conventional treatment, including $0.5 \mathrm{~L} / \mathrm{min}$ supplemental oxygen for $30 \mathrm{~min}, 200 \mu \mathrm{g}$ inhaled salbutamol, $40 \mu \mathrm{g}$ inhaled ipratropium, and $200 \mathrm{mg}$ intravenous hydrocortisone. The salbutamol and ipratropium were via metered-dose inhaler, without spacer. Along with the conventional therapy, the furosemide subjects received $4 \mathrm{~mL}$ inhaled furosemide $(40 \mathrm{mg}$ ), and the saline subjects received $4 \mathrm{~mL} 0.9 \%$ inhaled normal saline, via nebulizer (NE-U17, Omron Healthcare, Lake Forest, Illinois). All variables were measured again 1 hour after treatment. The primary end points were the changes in $\mathrm{FEV}_{1}$ and dyspnea severity. The secondary end points were the changes in the other parameters.

The data were analyzed using statistics software (SPSS 15.0, SPSS, Chicago, Illinois). The chi-square test was used for the analysis of categorical variables. The independent $t$ test was utilized to compare baseline variables between the study groups and the post-treatment changes. Results are reported as mean \pm SD. $P<.05$ was considered statistically significant.

\section{Results}

We enrolled 100 patients with COPD exacerbation. The mean age was $73.1 \pm 8.7$ years, 63 were male, and the mean baseline $\mathrm{FEV}_{1}$ was $53.8 \pm 4.4 \%$ of predicted (range 44-63\%) (Table 1). Before treatment, the only statistically significant differences between the furosemide and saline groups were in bicarbonate and heart rate (see Table 1). After treatment, dyspnea and $\mathrm{FEV}_{1}$ improved in both groups, but the improvement was significantly greater in the intervention group, except for oxygen saturation (Table 2). The subjects who presented with a lower FEV on admission had more benefit from furosemide than those who had a higher baseline FEV $_{1}$ (Figure). The mean arterial blood pressure and heart rate decreased in the furo- 
Table 1. Baseline Clinical and Laboratory Variables

\begin{tabular}{lccc}
\hline \hline & $\begin{array}{c}\text { Intervention } \\
\text { Group } \\
n=50\end{array}$ & $\begin{array}{c}\text { Placebo } \\
\text { Group } \\
n=50\end{array}$ & $P$ \\
\hline Age, y & $73.2 \pm 8.6$ & $73.0 \pm 9.0$ & .93 \\
Breathing frequency, & $26.4 \pm 6.3$ & $27.3 \pm 2.6$ & .39 \\
$\quad$ breaths/min & & & \\
Mean arterial blood & $108.4 \pm 16.9$ & $105.4 \pm 11.9$ & .31 \\
$\quad$ pressure, mm Hg & & & \\
Heart rate, beats/min & $88.9 \pm 17.5$ & $101.0 \pm 10.9$ & $<.001$ \\
$\mathrm{pH}$ & $7.29 \pm 0.06$ & $7.27 \pm 0.06$ & .08 \\
$\mathrm{P}_{\mathrm{aCO}}, \mathrm{mm} \mathrm{Hg}$ & $55.6 \pm 12.8$ & $51.8 \pm 6.8$ & .07 \\
$\mathrm{P}_{\mathrm{aO}}, \mathrm{mm} \mathrm{Hg}$ & $73.2 \pm 11.3$ & $76.7 \pm 6.7$ & .06 \\
$\mathrm{HCO}_{3}, \mathrm{mEq} / \mathrm{L}$ & $31.6 \pm 6.0$ & $28.7 \pm 2.5$ & $<.01$ \\
$\mathrm{~S}_{\mathrm{aO}}, \%$ & $84.8 \pm 9.6$ & $82.8 \pm 4.7$ & .18 \\
$\mathrm{FEV}_{1}, \%$ of predicted & $54.8 \pm 3.9$ & $52.7 \pm 4.6$ & .02 \\
$\mathrm{Dyspnea} \mathrm{score}$ & $5.6 \pm 0.9$ & $5.4 \pm 0.7$ & .26
\end{tabular}

$\overline{\text { Values are mean } \pm \mathrm{SD}}$

$\mathrm{S}_{\mathrm{aO}_{2}}=$ oxygen saturation measured via arterial blood sample

Table 2. Changes in Clinical and Laboratory Variables After Treatment

\begin{tabular}{|c|c|c|c|}
\hline & $\begin{array}{c}\text { Intervention } \\
\text { Group } \\
n=50\end{array}$ & $\begin{array}{c}\text { Placebo } \\
\text { Group } \\
n=50\end{array}$ & $P$ \\
\hline $\begin{array}{l}\text { Breathing frequency, } \\
\text { breaths/min }\end{array}$ & $-7.0 \pm 3.2$ & $-3.3 \pm 2.1$ & $<.001$ \\
\hline $\begin{array}{l}\text { Mean arterial blood } \\
\text { pressure, } \mathrm{mm} \mathrm{Hg}\end{array}$ & $-8.9 \pm 10.4$ & $0.6 \pm 7.3$ & $<.001$ \\
\hline Heart rate, beats/min & $-4.9 \pm 11.9$ & $0.4 \pm 6.8$ & .007 \\
\hline $\mathrm{pH}$ & $0.07 \pm 0.03$ & $0.04 \pm 0.02$ & $<.001$ \\
\hline $\mathrm{P}_{\mathrm{aCO}_{2}}, \mathrm{~mm} \mathrm{Hg}$ & $-1.3 \pm 6.5$ & $-5.4 \pm 4.5$ & $<.001$ \\
\hline $\mathrm{P}_{\mathrm{aO}_{2}}, \mathrm{~mm} \mathrm{Hg}$ & $12.6 \pm 5.2$ & $8.2 \pm 4.9$ & $<.001$ \\
\hline $\mathrm{HCO}_{3}^{-}, \mathrm{mEq} / \mathrm{L}$ & $1.9 \pm 3.8$ & $-2.2 \pm 1.6$ & $<.001$ \\
\hline $\mathrm{S}_{\mathrm{aO}_{2}}, \%$ & $7.4 \pm 7.4$ & $6.7 \pm 2.7$ & .54 \\
\hline $\mathrm{FEV}_{1}, \%$ of predicted & $11.5 \pm 3.6$ & $4.9 \pm 3.1$ & $<.001$ \\
\hline Dyspnea score & $-2.7 \pm 1.0$ & $-1.6 \pm 0.8$ & $<.001$ \\
\hline
\end{tabular}

semide group, while they slightly increased in the saline group, and the difference was statistically significant (see Table 2). $\mathrm{P}_{\mathrm{CO}_{2}}$ decreased after the treatment in both groups; however, the decrease was more noticeable in the placebo group $(P<.001$, Table 2$)$. Oxygen saturation increased in both groups, and the difference between the 2 groups was not statistically significant.

\section{Discussion}

Inhaled furosemide improved dyspnea and other physiologic respiratory parameters in patients with acute COPD

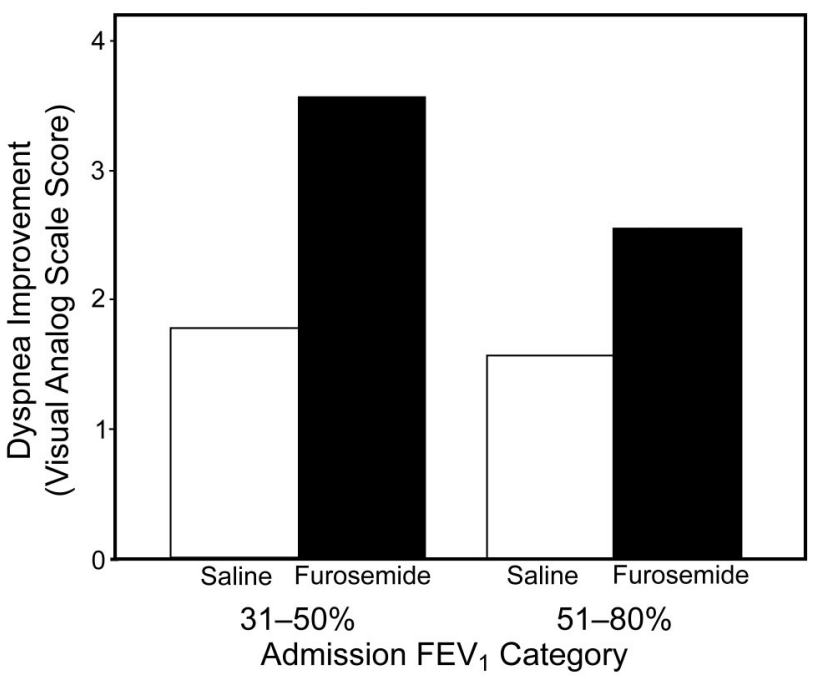

Figure. Dyspnea improvement following conventional treatment for COPD exacerbation plus either nebulized furosemide or placebo (saline), according to admission $\mathrm{FEV}_{1}$ category.

exacerbation. The furosemide group had a 1-unit visual analog scale better dyspnea improvement and a 4 breaths/ min better reduction in breathing frequency than the saline group. Those differences seem to us clinically important, considering the baseline values and the range of variations (see Table 1 and Table 2). Clinical importance refers to the magnitude of a given change, while statistical significance indicates that a given change is unlikely to be due to change or random error. Therefore, a change may be statistically significant but clinically unimportant. Severity of dyspnea was measured according to the subjects' perception. It could be expected that any improvement reported by the subjects should be clinically important to be considered as an improvement at all.

The $\mathrm{FEV}_{1}$ improvement was about $7 \%$ more with furosemide, which is similar to that in the Ong et al study (about $5 \%$ ). ${ }^{16} \mathrm{FEV}_{1}$ is highly predictive of clinical outcomes in patients with COPD exacerbation. Niewoehner et al found that relatively small differences in $\mathrm{FEV}_{1}$ have a substantial impact on clinical outcome. ${ }^{20}$ Among the subjects who received nebulized furosemide, those with lower baseline $\mathrm{FEV}_{1}$ had better dyspnea improvement (see the Figure). Since patients with lower $\mathrm{FEV}_{1}$ are less able to bronchodilate, this improvement might also be attributed to an effect of nebulized furosemide on dyspnea relief that is independent of bronchodilation. ${ }^{3,12}$

The effects of $\beta_{2}$-agonists and corticosteroids on gas exchange have been previously described in COPD patients. ${ }^{21-23}$ In this study we sought to determine how arterial blood gas values would change when nebulized furosemide is added to conventional therapy. The combination of $\mathrm{O}_{2}, \beta_{2}$-adrenoceptor agonist, anticholinergic, and corticosteroid plus furosemide increased $\mathrm{pH}$ and $\mathrm{P}_{\mathrm{aO}}$ signif- 


\section{The Adjunctive Effect of Nebulized Furosemide in COPD Exacerbation}

icantly more than the conventional treatment plus saline placebo; however, these improvements do not seem to be clinically important. The mean change of $\mathrm{P}_{\mathrm{aO}}$ contributed by furosemide was about $4 \mathrm{~mm} \mathrm{Hg}$, and for $\mathrm{pH}$ it was approximately 0.03 . These findings can be attributed to a reduction in breathing frequency, improved ventilation, and increased dynamic inspiratory capacity, as was proposed in a study by Jensen et al. ${ }^{17} \beta$-adrenergic agents transiently decrease $\mathrm{P}_{\mathrm{aO}}$ as a result of their pulmonary vasodilator effects. While patients with severe COPD have a limited ability to sustain a bronchodilation, increasing blood flow to poorly ventilated lung regions causes a ventilation-perfusion mismatch..$^{21,22,24}$ Nebulized furosemide may reverse that pathological process by improving ventilation, particularly in patients who require higher doses of $\beta_{2}$-adrenoceptor agonists.

In this study, $\mathrm{P}_{\mathrm{aCO}_{2}}$ decreased more in the placebo group, which would argue against a benefit from furosemide. Subjects in the intervention group had higher baseline $\mathrm{P}_{\mathrm{aCO}}$ and bicarbonate than the placebo group, and this may indicate more severe and prolonged exacerbation in the intervention group. These patients may require more time to compensate and decrease $\mathrm{P}_{\mathrm{aCO}}$, despite greater improvement in breathing frequency. Our findings are contrary to the findings by Jensen et al, who reported that furosemide had no effect in stable COPD subjects. ${ }^{17}$ However, our subjects were different from those in the Jensen study; our subjects were patients with COPD and an acute exacerbation who presented to the emergency department. Since exacerbation is often associated with hypoxia, hypercarbia, and acidosis, it is expected that these patients show physiologically different responses.

In this study, the mean bicarbonate level decreased in conventional therapy but increased in combination therapy with furosemide. The mean rise related to furosemide was about $4 \mathrm{mEq} / \mathrm{L}$. Considering the mean bicarbonate baseline level and its range of variation, this change could be considered clinically important. Consistent with its expected pharmacodynamic characteristics, systemic furosemide is capable of inducing a metabolic alkalosis by increasing urinary hydrogen $\left(\mathrm{H}^{+}\right)$loss. ${ }^{25}$ Although the effect of nebulized furosemide on dyspnea is likely to be independent of its systemic diuretic effect, ${ }^{18,26}$ the systemic effect of nebulized furosemide has not been ruled out. ${ }^{17}$ Both heart rate and blood pressure decreased in the furosemide group, by about 4 beats/min and $9 \mathrm{~mm} \mathrm{Hg}$, respectively, which is consistent with the results in the study by Rodriguez Vazquez et al ${ }^{13}$; however, these changes were not clinically important. The change in heart rate and blood pressure could explain functional cardiac effects related to this medication; however, considering multiple contributing factors, including patient anxiety and potential diuretic effects of furosemide, it may preclude a direct correlation between these findings.

\section{Limitations}

It is difficult to conduct a controlled study of patients in COPD exacerbation. Our furosemide subjects had higher baseline bicarbonate, $\mathrm{P}_{\mathrm{aCO}}$, and dyspnea, and lower $\mathrm{P}_{\mathrm{aO}}$. This may indicate more severe exacerbation in the furosemide group. On the other hand, baseline $\mathrm{FEV}_{1}$ was higher in the furosemide group. Altogether, these findings may indicate that the furosemide subjects had milder COPD but more severe exacerbations. It might be argued that furosemide subjects had more capability to decrease dyspnea due to higher baseline $\mathrm{FEV}_{1}$, but the furosemide subjects with lower baseline $\mathrm{FEV}_{1}$ had significantly greater dyspnea improvement than the subjects with higher baseline $\mathrm{FEV}_{1}$ (see Fig. 1). We did not assess the diuretic effect of nebulized furosemide, and the possible systemic effects of nebulized furosemide could not be confirmed in this study.

\section{Conclusions}

The combination of nebulized furosemide with conventional therapy improved dyspnea and physiologic respiratory parameters in patients with COPD exacerbation. Furosemide may provide an additional therapeutic option for patients with COPD exacerbation. Systemic effects of nebulized furosemide should be considered in future investigations.

\section{ACKNOWLEDGMENTS}

We thank Bita Pourmand, Research Development Centre, Sina Hospital, Tehran, Iran, for her valuable help in editing the manuscript.

\section{REFERENCES}

1. Rabe KF, Hurd S, Anzueto A, Barnes PJ, Buist SA, Calverley P, et al. Global strategy for the diagnosis, management, and prevention of chronic obstructive pulmonary disease: GOLD executive summary. Am J Respir Crit Care Med 2007;176(6):532-555.

2. Fromer L, Cooper CB. A review of the GOLD guidelines for the diagnosis and treatment of patients with COPD. Int J Clin Pract 2008;62(8):1219-1236.

3. Ora J, Jensen D, O'Donnell DE. Exertional dyspnea in chronic obstructive pulmonary disease: mechanisms and treatment approaches. Curr Opin Pulm Med 2010;16(2):144-149.

4. Seamark DA, Seamark CJ, Halpin DM. Palliative care in chronic obstructive pulmonary disease: a review for clinicians. J R Soc Med 2007;100(5):225-233.

5. Horton R, Rocker G. Contemporary issues in refractory dyspnoea in advanced chronic obstructive pulmonary disease. Curr Opin Support Palliat Care 2010;4(2):56-62.

6. Undem BJ, Kollarik M. The role of vagal afferent nerves in chronic obstructive pulmonary disease. Proc Am Thorac Soc 2005;2(4):355360; discussion 371-352.

7. Uronis HE, Currow DC, Abernethy AP. Palliative management of refractory dyspnea in COPD. Int J Chron Obstruct Pulmon Dis 2006; 1(3):289-304

8. Nishino T. Dyspnoea: underlying mechanisms and treatment. Br J Anaesth 2011;106(4):463-474. 


\section{The Adjunctive Effect of Nebulized Furosemide in COPD Exacerbation}

9. Kallet RH. The role of inhaled opioids and furosemide for the treatment of dyspnea. Respir Care 2007;52(7):900-910.

10. Sudo T, Hayashi F, Nishino T. Responses of tracheobronchial receptors to inhaled furosemide in anesthetized rats. Am J Respir Crit Care Med 2000;162(3 Pt 1):971-975.

11. Moosavi SH, Binks AP, Lansing RW, Topulos GP, Banzett RB, Schwartzstein RM. Effect of inhaled furosemide on air hunger induced in healthy humans. Respir Physiol Neurobiol 2007;156(1):1-8.

12. Nishino T, Ide T, Sudo T, Sato J. Inhaled furosemide greatly alleviates the sensation of experimentally induced dyspnea. Am J Respir Crit Care Med 2000;161(6):1963-1967.

13. Rodriguez Vazquez JC, Pino Alfonso PP, Gassiot Nuno C, Paez Prats I, Fernandez Manzano E. Assessment of the bronchodilator effect of inhaled furosemide compared to salbutamol in asthmatic patients. J Investig Allergol Clin Immunol 1998;8(2):115-118.

14. Shimoyama N, Shimoyama M. Nebulized furosemide as a novel treatment for dyspnea in terminal cancer patients. J Pain Symptom Manage 2002;23(1):73-76.

15. Kohara H, Ueoka H, Aoe K, Maeda T, Takeyama H, Saito R, et al. Effect of nebulized furosemide in terminally ill cancer patients with dyspnea. J Pain Symptom Manage 2003;26(4):962-967.

16. Ong KC, Kor AC, Chong WF, Earnest A, Wang YT. Effects of inhaled furosemide on exertional dyspnea in chronic obstructive pulmonary disease. Am J Respir Crit Care Med 2004;169(9):1028-1033.

17. Jensen D, Amjadi K, Harris-McAllister V, Webb KA, O'Donnell DE. Mechanisms of dyspnoea relief and improved exercise endurance after furosemide inhalation in COPD. Thorax 2008;63(7):606-613.

18. Currow DC, Ward AM, Abernethy AP. Advances in the pharmacological management of breathlessness. Curr Opin Support Palliat Care 2009;3(2):103-106
19. American Thoracic Society. Standards for the diagnosis and care of patients with chronic obstructive pulmonary disease. Am J Respir Crit Care Med 1995;152(5 Pt 2):S77-121.

20. Niewoehner DE, Collins D, Erbland ML. Relation of FEV 1 to clinical outcomes during exacerbation of chronic obstructive pulmonary disease. Department of Veterans Affairs Cooperative Study Group. Am J Respir Crit Care Med 2000;161(4 Pt 1):1201-1205.

21. Khoukaz G, Gross NJ. Effects of salmeterol on arterial blood gases in patients with stable chronic obstructive pulmonary disease. Comparison with albuterol and ipratropium. Am J Respir Crit Care Med 1999;160(3):1028-1030.

22. Whale CI, Sovani MP, Mortimer K, Oborne J, Cooper S, Harrison $\mathrm{TW}$, et al. Effects of rac-albuterol on arterial blood gases in patients with stable hypercapnic chronic obstructive pulmonary disease. Br J Clin Pharmacol 2006;62(2):153-157.

23. Ando F, Ruggeri P, Girbino G, Cazzola M. Tiotropium and salmeterol/fluticasone combination do not cause oxygen desaturation in COPD. Respir Med 2008;102(6):815-818.

24. Stephenson A, Seitz D, Bell CM, Gruneir A, Gershon AS, Austin PC, et al. Inhaled anticholinergic drug therapy and the risk of acute urinary retention in chronic obstructive pulmonary disease: a population-based study. Arch Intern Med 2011;171(10):914920

25. Brijker F, Heijdra YF, van den Elshout FJ, Folgering HT. Discontinuation of furosemide decreases $\mathrm{P}_{\mathrm{aCO}_{2}}$ in patients with COPD. Chest 2002;121(2):377-382.

26. Minowa Y, Ide T, Nishino T. Effects of inhaled furosemide on $\mathrm{CO}_{2}$ ventilatory responsiveness in humans. Pulm Pharmacol Ther 2002;15(4):363-368

This article is approved for Continuing Respiratory Care Education credit. For information and to obtain your CRCE

(free to AARC members) visit

www.rcjournal.com 